\title{
СПОСОБ ПРОГНОЗИРОВАНИЯ РИСКА ОТДАЛЕННОГО НЕБЛАГОПРИЯТНОГО ИСХОДА У ПАЦИЕНТОВ С ОСТРЫМ КОРОНАРНЫМ СИНДРОМОМ И САХАРНЫМ ДИАБЕТОМ 2 ТИПА
}

\author{
Никитина Е.А., Елсукова О.С., Метелев И.С.
}

ФГБОУ ВО «Кировский государственный медицинский университет» Минздрава России, Киров

ЦЕЛЬ: изучить факторы, влияющие на прогноз у пациентов с острым коронарным синдромом (ОКС) и сопутствующим сахарным диабетом 2 типа (СД2). На основании полученных данных, разработать логитмодель прогнозирования риска неблагоприятного исхода у пациентов с СД2 в течение 12 месяцев после эпизода ОКС.

МАТЕРИАЛЫ И МЕТОДЫ: обследовано 120 пациентов с СД2, из них 49 мужчин и 71 женщина, в воз-

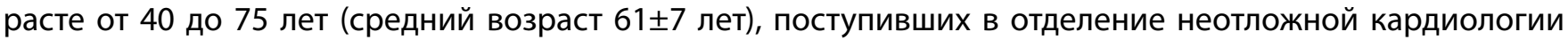
с ОКС. Пациенты обследовались и лечились в соответствии с клиническими рекомендациями и федеральными стандартами ведения больных ОКС. Оценена частота неблагоприятного исхода в течение 12 месяцев после ОКС, включившего развитие сердечно-сосудистой смерти, инфаркта миокарда (ИМ), реваскуляризации миокарда. Дополнительно проанализирована частота достижения комбинированной конечной точки (ККТ), включившей ИМ и/или сердечно-сосудистую смерть и/или реваскуляризацию миокарда. В зависимости от развития неблагоприятного исхода, пациенты разделены на две группы: 1 группа - 34 пациента, из них 13 мужчин и 21 женщина, с наступившим неблагоприятным исходом, 2 группа 86 пациентов, из них 36 мужчин и 50 женщин, без неблагоприятного исхода. С помощью логистической регрессии, определены факторы, ассоциированные с наступлением ККТ. С целью прогнозирования риска развития неблагоприятного отдаленного исхода у пациентов с ОКС и СД2 построена модель бинарной логистической регрессии.

РЕЗУЛЬТАТЫ: в результате проведенного исследования, установлены независимые факторы, ассоциированные с развитием неблагоприятного исхода в течение 12 месяцев у пациентов с СД2 после ОКС: гипертриглицеридемия, снижение вариабельности ритма сердца (SDNN<80 мс), наличие трех и более сегментов коронарных артерий со значимым стенозированием, отсутствие реваскуляризации миокарда в остром периоде. При помощи выявленных независимых факторов, создана математическая модель прогнозирования неблагоприятного исхода в течение 12 месяцев у пациентов с ОКС на фоне СД2. Оптимальный порог отсечения составил 0,37. При данном пороге отсечения, диагностическая чувствительность составила 88\%, диагностическая специфичность 66\%.

Выводы: данная модель показала высокую чувствительность и диагностическую точность в прогнозировании неблагоприятного исхода в течение 12 месяцев у пациентов с ОКС и сопутствующим СД2. 